\title{
Révolutionnaires et émigrés. Transfer und Migration zwischen Frankreich und Deutschland, 1789-1806, sous la direction de Daniel Schônpflug et Jùrgen Voss
} Jean-Clément Martin

\section{(2) OpenEdition \\ 1 Journals \\ Édition électronique \\ URL : https://journals.openedition.org/ahrf/10813 \\ DOI : 10.4000/ahrf.10813 \\ ISSN : 1952-403X \\ Éditeur : \\ Armand Colin, Société des études robespierristes}

\section{Édition imprimée}

Date de publication : 1 septembre 2003

ISSN : 0003-4436

\section{Référence électronique}

Jean-Clément Martin, «Révolutionnaires et émigrés. Transfer und Migration zwischen Frankreich und Deutschland, 1789-1806, sous la direction de Daniel Schônpflug et Jùrgen Voss », Annales historiques de la Révolution française [En ligne], 333 | juillet-septembre 2003, mis en ligne le 07 décembre 2009, consulté le 23 avril 2022. URL : http://journals.openedition.org/ahrf/10813 ; DOI : https://doi.org/ 10.4000/ahrf.10813

Ce document a été généré automatiquement le 23 avril 2022.

Tous droits réservés 


\title{
Révolutionnaires et émigrés. Transfer und Migration zwischen Frankreich und Deutschland, 1789-1806, sous la direction de Daniel Schônpflug et Jùrgen Voss
}

\author{
Jean-Clément Martin
}

\section{RÉFÉRENCE}

Révolutionnaires et émigrés. Transfer und Migration zwischen Frankreich und Deutschland, 1789-1806,sous la direction de Daniel Schônpflug et Jùrgen Voss, Stuttgart, Thorbecke, 2002, 250 p., ISBN 3-7995-7450-6.

1 Le livre rassemble les communications données à l'occasion d'un atelier organisé par l'Institut historique allemand à Paris le 16 septembre 1999, qui a mis en œuvre la notion de transfert culturel pour apprécier selon cette perspective, maintenant bien connue, les rapports entre la France et l'Allemagne de 1789 et 1806, pour traiter de la propagande révolutionnaire et des jacobins, de l'iconographie et de la culture, enfin des émigrés. Il s'agit donc d'une série d'études de cas.

2 Ainsi Erich Pelzer montre comment certains intellectuels allemands contrerévolutionnaires popularisent l'image négative du Jacobin français après les premières années de la Révolution et au moment où la guerre vient changer la perception des idéaux français. Gildas Pasetzky évoque l'exemple de la mission politique de deux envoyés autrichiens, Held et Denkmann, en 1794 à Paris, essayant, au nom d'un soutien à la cause révolutionnaire, de faire cesser rapidement la guerre pour le profit des peuples, y compris du peuple polonais ! Cette mission, irréaliste, bute en France sur la méfiance envers les étrangers, si bien qu'ils passèrent trois mois en prison, en vain. La 
conséquence fut que leurs amis restés à Vienne furent réprimés. Daniel Schônpflug, auteur d'une thèse sur la terreur à Strasbourg, montre comment le Club des Jacobins de la ville passe d'une politique d'échanges avec le monde germanique en 1790 en bastion de guerre contre l'Empire et la pensée allemande. Le changement des recrutements et de la conjoncture politique expliquent ce revirement vers l'exclusion, posant les Jacobins comme les champions de l'unité face à la bourgeoisie germanophone et modérée de la ville. Les origines locales de la xénophobie trouvent ainsi une traduction politique radicale. À propos de Strasbourg toujours, Claude Bctzingcr démontre que la personnalité d'Euloge Schneider, clerc défroqué, journaliste puis accusateur public, est susceptible de deux lectures selon qu'on l'appréhende comme Jacobin vu de France ou «deutscher Jakobiner ». Cette dénomination est trop floue pour désigner un groupe précis, mais consacrée par l'usage, elle amalgame les authentiques acteurs politiques à des sympathisants des événements survenus en France. Si bien que Schneider est un "Jakobiner» radical tout en étant considéré comme un Jacobin douteux par les représentants en mission (Saint-Just et Lebas) qui le dénoncèrent ; il finit guillotiné en avril 1794. Susanne Lachcnicht s'intéresse aux émigrés allemands venus en France par idéal révolutionnaire. Ils se trouvèrent rapidement isolés dans le pays après 1794, alors qu'ils espéraient possible la création d'une république indépendante en Allemagne, la politique du Directoire les déçut totalement. Michael Martin, dans son texte concernant la Révolution à Landau, enclave française en territoire allemand, expose enfin comment la population luthérienne se rallie à la Révolution - contre les catholiques - avant de faire l'expérience amère de l'incompréhension des politiques français en 1793. Malgré tout la bourgeoisie locale garda un enracinement favorable à la politique révolutionnaire.

Dans un autre registre, plus culturel, Wolfgang H. Stein étudiant les en-têtes emblématiques des administrations françaises en Rhénanie entre 1794 et 1804, conclut que les vignettes servent autant à attester la volonté de marquer un acte révolutionnaire qu'à insister sur le besoin de légitimation exprimé par l'administration, si bien que les vignettes servent moins à affirmer une pensée révolutionnaire qu'à permettre l'établissement de l'État. Elisabeth Reuss s'intéresse à la dispersion, de 1794 à 1814, des fonds d'archives de Cologne provoquée par les occupations françaises, pour nuancer les accusations récurrentes contre les Français, accusés de dévastations et de vols, el conclure sur la réorganisation qui eut lieu de fait pendant cette période. Dernier domaine exploré, la situation des émigrés, ouvert par Christian Henke qui reprend ici la thèse soutenue récemment sur Coblence et son image, pour montrer comment la ville est devenue le centre politique de l'émigration et surtout comment elle est devenue un symbole détaché de la réalité dans l'imaginaire des politiques français. L'accueil des émigrés français en Westphalie est l'objet de l'attention de Peter Veddeler qui insiste sur la double politique des gouvernements allemands, triant les émigrés selon l'intérêt de leurs propres sujets; la Prusse fut accueillante aux grands noms français, peu aux émigrés ordinaires, Munster accueillit prioritairement les clercs. Thomas Hôpel suit les émigrés français en Saxe et en Prusse en renforçant l'idée de la suspicion des gouvernements envers les "étrangers", quels qu'ils soient, la Prusse essayant d'adopter une position plus bureaucratique dissociant citoyen d'étranger, selon les besoins de l'État, la Saxe gardant des positions plus traditionnelles d'exclusion/ inclusion selon les besoins de l'économie sans vrai souci de contrôle étatique. Karine Rance, utilisant les Mémoires des émigrés français en Allemagne, conclut que ceux-ci critiquent fortement Coblence, pratiquement comme le font les révolutionnaires, mais 
qu'ils le font a posteriori pour expliquer par là l'échec de l'émigration. Serguey Torotkov étudie la transformation sociale de la colonie française de Saint-Pétersbourg pour insister sur la mutation provoquée par l'arrivée d'émigrés dans une colonie relativement démocratique, mais qui continue de réagir d'une façon très diverse face à des expériences européennes jugées exotiques.

4 Dans une conclusion méthodologique, Pierre-André Bois reprend les différentes variations du transfert selon qu'il se fait des expériences géographiques (Landau), conceptuelles (autour de Strasbourg et des Jacobins, surtout face aux conceptions antagonistes des Lumières), ou qu'il est lié à l'émigration et P.-A. Bois propose l'idée que les émigrés plutôt que de n'avoir rien oublié ni rien appris, n'avaient plus sûrement rien compris. La réflexion mérite de retenir l'attention car c'est sans doute cela qui est au cœur de ce livre sur la complexité des transferts, interdisant que l'on s'arrête trop vite à des échanges simples et que l'on essaie de penser les adaptations délicates d'une culture ou d'une situation à l'autre. 